\section{Easter Lilies React Differently to Short- or Long- term Exposure of Ethylene or Methane at Different Stages of Forcing}

\author{
Theo J. Blom, ${ }^{1}$ \\ Wayne Brown, ${ }^{2}$ George C.L. \\ Chu, ${ }^{1}$ Wei Tang Liu, ${ }^{1}$ \\ Lisa Skog ${ }^{1}$
}

\begin{abstract}
Additional indeX words. CTF, controlled temperature forcing, Lilium longiflorum
\end{abstract}

Summary. The sensitivity of easter lilies (Lilium longiflorum) to either ethylene or methane (products of incomplete burning in gas-fired unit heaters) was tested during rooting [ 3 weeks at 18 ${ }^{\circ} \mathrm{C}\left(65^{\circ} \mathrm{F}\right)$ ], vernalization [ 6 weeks at 6 $\left.{ }^{\circ} \mathrm{C}\left(43{ }^{\circ} \mathrm{F}\right)\right]$ and subsequent greenhouse forcing ( 15 weeks at $18^{\circ} \mathrm{C}$ ). Starting at planting, easter lilies were exposed for one of seven consecutive 3week periods (short-term), or for 0,3 , $6,9,12,15,18$, or 21 weeks starting at planting (long-term) to either ethylene or methane at an average concentration of 2.4 and $2.5 \mu \mathrm{L} \cdot \mathrm{L}^{-1}$ (ppm), respectively. Short- or longterm exposure to ethylene during rooting and vernalization had no effect on the number of buds, leaves, or plant height but increased the number of days to flower. Short-term exposure within 6 weeks after vernalization reduced the number of buds by 1 bud/ plant compared to the control (no ethylene exposure). However, extensive bud abortion occurred when plants were exposed to ethylene during the flower development phase. Long-term exposure to ethylene from planting until after the flower initiation period resulted in only two to three buds being initiated, while continued long-

${ }^{1}$ Department of Plant Agriculture, University of Guelph, 4890 Victoria Ave. North, Vineland Station, ON, Canada LOR 2E0.

${ }^{2}$ Ontario Ministry of Agriculture, Food and Rural Affairs (same address) term exposure until flowering caused all flower buds to abort. Short-term exposure to methane at any time had no effect on leaf yellowing, bud number, bud abortion, or height and had only a marginal effect on production time. Long-term exposure to methane from planting until the end of vernalization increased both the number of buds, leaves and height without affecting forcing time, leaf yellowing or bud abortion.

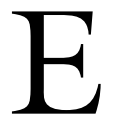
thylene and related gaseous compounds reduce height, reduce or abort flower buds and induce premature leaf senescence of easter lilies (Mason and Miller, 1991; Prince and Cunningham, 1991; Wees, 1993). Most studies report effects on emerged plants to low ethylene concentrations $\left(0.01\right.$ to $\left.0.1 \mu \mathrm{L} \cdot \mathrm{L}^{-1}\right)$ (Blankenshipetal., 1993). However there is little information on the comparative sensitivity of easter lilies to ethylene during different stages of development, including rooting, vernalization, flowerinitiation and flower development.

Easter lilies are often exposed to high levels of ethylene $\left(>0.5 \mu \mathrm{L} \cdot \mathrm{L}^{-1}\right)$ for long periods of time due to incomplete combustion of fossil fuels in unit heaters, tow motors, carbon dioxide burners, or to methane, an air pollutant derived from leaky pipefittings and/or incomplete combustion in natural gasfired unit heaters (Mason and Miller, 1991; Rhoads et al., 1973). The symptoms expressed by flowering plants when exposed to ethylene include: reduced number of flower buds, leaf curl, very short internodes, but increased crop uniformity and premature lower leaf senescence, many of which often appear during the early forcing stages. It is unknown whether expression of these symptoms early in forcing is due to the malfunctioning of forced air heaters during the winter because of the high heat demand combined with minimal ventilation or because the sensitivity of lilies to ethylene is greater during early compared to later stages of forcing. When ethylene damage occurs in a greenhouse, methane is also usually present (personal observation). Our purpose to include methane was to determine whether methane is a contributing factor to the observed symptoms associated with ethylene. No published information exists on the effect of methane gas on lilies. The objectives of this study were to determine the sensitivity of easter lilies to ethylene and methane during different stages of plant development during forcing.

\section{Material and methods}

Bulbs of easter lily 'Nellie White' [20 to $23 \mathrm{~cm}$ (8 to 9 inches) circumference, dug on 14 Oct. 1999, by the United Bulb Company, Smith River, Calif.] were packed in wooden crates and shipped in temperature-controlled $\left[15\right.$ to $16^{\circ} \mathrm{C}\left(58\right.$ to $\left.\left.60^{\circ} \mathrm{F}\right)\right]$ trailers to Ontario, Canada. Upon arrival $(25$ Oct. 1999), bulbs were dipped for $30 \mathrm{~min}$ in a mixture containing dicofol $[0.525$ $\left.\mathrm{g} \cdot \mathrm{L}^{-1}(525 \mathrm{ppm})\right]$, metalaxyl [16.8 $\left.\mathrm{mg} \cdot \mathrm{L}^{-1}(16.8 \mathrm{ppm})\right]$, and benomyl $[0.5$ $\left.\mathrm{g} \cdot \mathrm{L}^{-1}(500 \mathrm{ppm})\right]$. Individual bulbs were planted the following day (week 43) in a $15-\mathrm{cm}$-diameter standard plastic pot [1.6-L (0.4-gal)] filled with Sunshine no. 4 growing substrate (SunGro Horticulture, Westerville, Ohio). At this time, the bulb weighed $160 \pm 15 \mathrm{~g}$ (5.6 $\pm 0.5 \mathrm{oz}$ ) (mean of 8 ). Observations under a dissecting microscope indicated that each had $46 \pm 8$ leaf primordia and the meristem was $2.1 \pm 0.7 \mathrm{~mm}(0.1$ inch) above the basal plate.

The bulbswere rooted in the dark for 3 weeks at $18^{\circ} \mathrm{C}$, vernalized in coolers for 6 weeks at $6^{\circ} \mathrm{C}$, and then greenhouse forced under ambient conditions (42\% northern latitude) for 15 weeks at $18^{\circ} \mathrm{C}$. The total production time ( 24 weeks) was dividedintoeight 3-weekperiods, of which only the firstseven were treatment periods. Plants were either exposed to ethylene or methane during a single 3-week treatment period (short-term) (Fig. 1A), or starting at planting for increasing multiple treatment periods of $3,6,9,12,15,18$, or 21 weeks (long-term) (Fig. 1B). The single 3week treatment periods coincided with rooting (first period), vernalization (second and third), flower initiation (fourth and fifth), and flower development (sixth and seventh). The control plants were held under ambient conditions.

Ethylene/methane treatment. Planted bulbs were placed in sealed $300-\mathrm{L}\left(0.4 \mathrm{yd}^{3}\right)$ polyethylene $[150 \mu \mathrm{m}$ (6 mil, 0.006 inches) thick] bags and kept in temperature-controlled chambers for the rooting and vernalization phase (week 43 to week 52, 1999). Either ethylene (99.9\%; Praxair Canada Inc., Mississauga, Ont., Canada), or methane (99.97\%; Praxair Canada Inc. Mississauga, Ont., Canada) was injected at $2 \mu \mathrm{L} \cdot \mathrm{L}^{-1}$ into each bag using a syringe. Twice per day (early morning and late afternoon), gas samples were withdrawn from each bag using a $10-\mathrm{mL}$ gas-tight 
syringe for immediate analysis of methane and ethylene concentrations using gas chromatography (model GC-8A; Shimadzu Corp., Kyoto, Japan) equipped with two flame ionization detectors and two 3.2-mm outer diameter $\times 244-\mathrm{cm}$ long, stainless steel columns packed with $80 / 100$ mesh of Porapak Q (part no. 27060; Waters Associates Inc., Milford, Mass.). Concentration adjustments in the bags were made on a daily basis as necessary. Oxygen and carbon dioxide concentrations were monitored in the treatment bags at the same time with a NOVA analyzer (model 308BD; Nova Analytical Systems Inc., Hamilton Ont., Canada). Hydrated lime was added to the plastic bags to absorb carbon dioxide $\left(\mathrm{CO}_{2}\right)$ and to keep its level below $500 \mu \mathrm{L} \cdot \mathrm{L}^{-1}$. Control plants were kept in separate but similar temperature-controlled rooms without any gas treatments.

During the greenhouse forcing phase [28 Dec. 1999 (week 52) until 21 Mar. 2000 (week 12)], the individual gases, ethylene and methane, were injected on a continuous basis into two separate freestanding double-layered polyethylene covered greenhouses [200 $\mathrm{m}^{2}\left(2200 \mathrm{ft}^{2}\right)$ each]. A double layered acrylic greenhouse $\left(200 \mathrm{~m}^{2}\right)$ was used for the control (ambient). The flow rate of gas injected into each greenhouse from a cylinder containing either pressurized methane or ethylene was controlled by a flowmeter (model 601; Matheson of Canada Ltd., Whitby, Ont., Canada). Ethylene and methane levels in the greenhouse compartments were sampled and monitored similarly (twice daily) as stated above for the treatment bags. The plants were placed on greenhouse benches $\left[25 / \mathrm{m}^{2}\left(2.3 / \mathrm{ft}^{2}\right)\right]$. Once a treatment period was completed, the plants were moved to the greenhouse $\left(200 \mathrm{~m}^{2}\right)$, where the untreated plants were grown. After 21 Mar. 2000 (end of period 7), all plants were grown in the ambient greenhouse until flowering. The overall means $\left(\mu \mathrm{L} \cdot \mathrm{L}^{-1} \pm \mathrm{SD}\right)$ for all seven periods were $2.4 \pm 1.3$ and $2.5 \pm 1.3$ for the ethylene and methane, respectively. It should be noted that the background level of methane in the ethylene chambers and ambient greenhouse compartments was $0.65 \pm 0.09 \mu \mathrm{L} \cdot \mathrm{L}^{-1}$.

Weekly, from planting until floral initiation was completed microscopically (Stage F; De Hertogh et al., 1976), three bulbs of the control plants were dissected, and the number of leaves, meristem length and stage of flower initiation in the apical meristem were recorded. With the control plants, flower initiation was completed on 1 Feb. 2000 (Fig. 1A and B).

During greenhouse forcing under ambient conditions, plants were grown according to commercially accepted practices with a $-5^{\circ} \mathrm{C}\left(-9^{\circ} \mathrm{F}\right)$ temperature difference between day and night. The same 24 -h average daily temperature $\left[18 \pm 0.5{ }^{\circ} \mathrm{C}\left(65 \pm 1.0^{\circ} \mathrm{F}\right)\right]$ was maintained in all three greenhouse compartments throughout forcing.

At first open flower (beginning of
April), the following characteristics were recorded for each plant: date of flowering of first primary flower, stem height (from rim of pot to base of inflorescence), number of green and yellow leaves $(>50 \%$ yellow), number of healthy and aborted buds (visual observation), and stem diameter at $1 / 4,1 / 2$, or $3 / 4$ of the stem height. When first primary flowerwas aborted, the above parameters were measured at the end of April. The experiment was a splitplot design with the type of gas as the main factor, plants as replications, and both exposure type (short- and long-term) and

\begin{tabular}{|c|c|c|c|c|c|c|c|c|}
\hline \multirow{2}{*}{$\begin{array}{l}\text { Year } \\
\begin{array}{l}\text { Forcing } \\
\text { weeks }\end{array}\end{array}$} & \multicolumn{3}{|c|}{1999} & \multicolumn{5}{|c|}{2000} \\
\hline & $0-3$ & $3-6$ & $6-9$ & $9-12$ & $12-15$ & $15-18$ & $18-21$ & $21-24$ \\
\hline $\begin{array}{l}\text { Plant } \\
\text { development }\end{array}$ & Rooting & \multicolumn{2}{|c|}{ Vernalization } & \multicolumn{2}{|c|}{ Flower initiation } & \multicolumn{3}{|c|}{ Flower development } \\
\hline \multirow[t]{2}{*}{ Temp. $\left[{ }^{\circ} \mathrm{C}\left({ }^{\circ} \mathrm{F}\right)\right]$} & $18(65)$ & \multicolumn{2}{|c|}{$6(43)$} & \multicolumn{5}{|c|}{$18(65)$} \\
\hline & \multicolumn{8}{|c|}{ Control } \\
\hline & $f_{15}$ & & & & & & & \\
\hline & & 4 & & & & & & \\
\hline & & & & & & & & \\
\hline & & & & 17 & & & & \\
\hline & & & & & 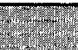 & & & \\
\hline & & & & & & & & \\
\hline & & & & & & & & \\
\hline
\end{tabular}

Fig. 1B Long-term exposure

\begin{tabular}{|c|c|c|c|c|c|c|c|c|}
\hline Year & \multicolumn{3}{|c|}{1999} & \multicolumn{5}{|c|}{2000} \\
\hline $\begin{array}{l}\text { Forcing } \\
\text { weeks }\end{array}$ & $0-3$ & 3-6 & $6-9$ & $9-12$ & $12-15$ & $15-18$ & $18-21$ & $21-24$ \\
\hline $\begin{array}{l}\text { Plant } \\
\text { development }\end{array}$ & Rooting & \multicolumn{2}{|c|}{ Vernalization } & \multicolumn{2}{|c|}{ Flower initiation } & \multicolumn{3}{|c|}{ Flower development } \\
\hline \multirow[t]{2}{*}{ Temp. $\left[{ }^{\circ} \mathrm{C}\left({ }^{\circ} \mathrm{F}\right)\right]$} & $18(65)$ & \multicolumn{2}{|c|}{$6(43)$} & \multicolumn{5}{|c|}{$18(65)$} \\
\hline & \multicolumn{8}{|c|}{ Control } \\
\hline & $y=-4$ & & & & & & & \\
\hline & 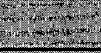 & 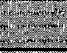 & & & & & & \\
\hline & 2 & testo & 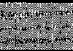 & & & & & \\
\hline & 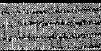 & 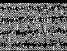 & 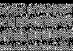 & 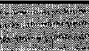 & & & & \\
\hline & 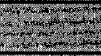 & 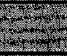 & 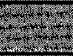 & textest & 5 & & & \\
\hline & 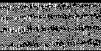 & 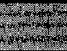 & 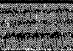 & 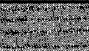 & 25 & 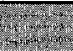 & & \\
\hline & & & 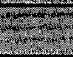 & 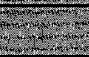 & & 5 & 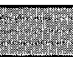 & \\
\hline
\end{tabular}

Date: 26 Oct. 16 Nov. 7 Dec. 28 Dec. 18 Jan. 8 Feb. 29 Feb. 21 Mar.

Exposure to ethylene $\left[2.4 \mu \mathrm{L} \cdot \mathrm{L}^{-1}(\mathrm{ppm})\right]$ or methane $\left(2.5 \mu \mathrm{L} \cdot \mathrm{L}^{-1}\right)$

No exposure to either ethylene or methane (ambient)

Fig. 1. The schedules for short-term (A) and long-term (B) exposure to either ethylene ormethane for easter lily 'Nellie White'. 
2A. Buds

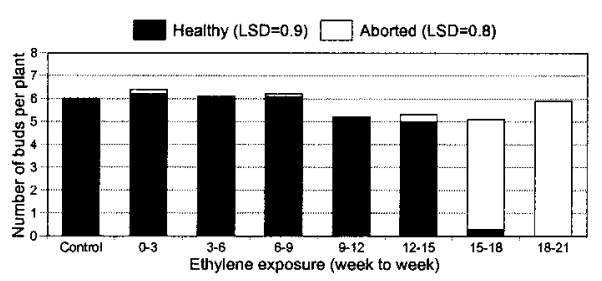

2C. Height

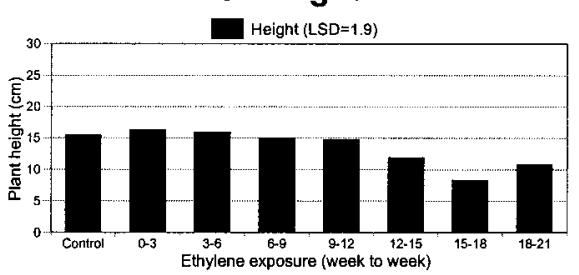

2B. Leaves
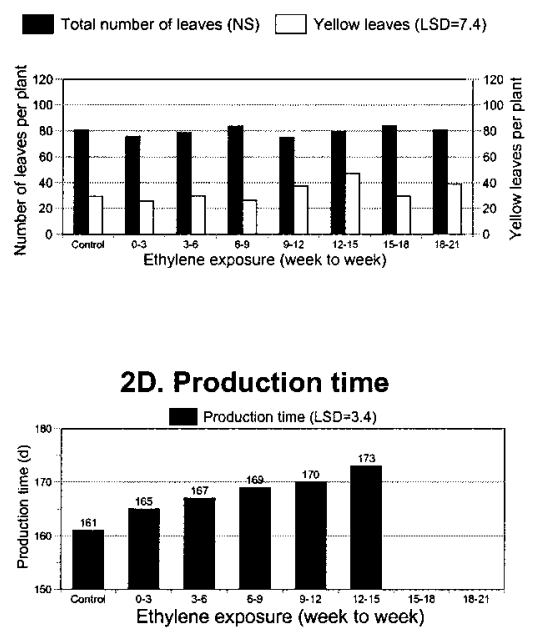

Fig. 2. The effect of timing of short-term ( 3 weeks) exposure to ethylene on the number of buds (healthy and aborted), number of leaves (total and yellow), plant height, and production time (planting to flowering) for easter lily Nellie White'. Planting and selected exposures commenced 26 Oct. (week 0 ). Values for least significant difference (LSD) are indicated whenever significant by analysis of variance at $P \leq 0.05 .1 \mathrm{~cm}=0.4$ inches.

periods ( 7 plus control) as subplot factors. There were 10 plants for each gas $\times$ exposure type $\times$ treatment unit. Preliminary analysis showed that the whole plot error mean squares were similar to subplot error mean squares. Consequently, the data were analyzed as a completely randomized design. Due to significant effects and interactions among gas, exposure type and treatment period on most plant parameters, the results are presented by gas and exposure type, and treatment period. All data were subjected to analysis of variance (Proc ANOVA, SAS Inst., Cary, N.C.). The means of treatment periods were separated by least significant difference (LSD) for both the ethylene and methane treatments. Each gas by exposure (shortand long-term) combination wasanalyzed separately.

\section{Results and discussion}

\section{SHORT-TERM ETHYLENE EXPOSURE.}

Single 3-week exposures to ethylene during rooting (week 0 to 3 ) and vernalization (week 3 to 6 and week 6 to 9 ) did not affect the number of healthy or aborted $(<0.2 /$ plant $)$ buds, the number of leaves (total and yellow), or plant height, but increased production time (period from planting to first flower open) between 4 and $8 \mathrm{~d}$ (Fig. 2A-D). A single 3-week exposure during the flower initiation phase (week 9 to 12 and week 12 to 15 ) significantly reduced the number of healthy buds by 1.0/plant and plant height but increased production time by about 9 to $12 \mathrm{~d}$ compared to the control plants. Exposure during flower development (week 15 to 18 and week 18 to 21 ) caused almost all buds to abort, and the plants were shorter than those plants exposed in periods of week 9 to 12 and week 12 to 15. During week 15 to 18 and week 18 to 21 most buds aborted (Fig. 2A), and thus the date of first open flower could not
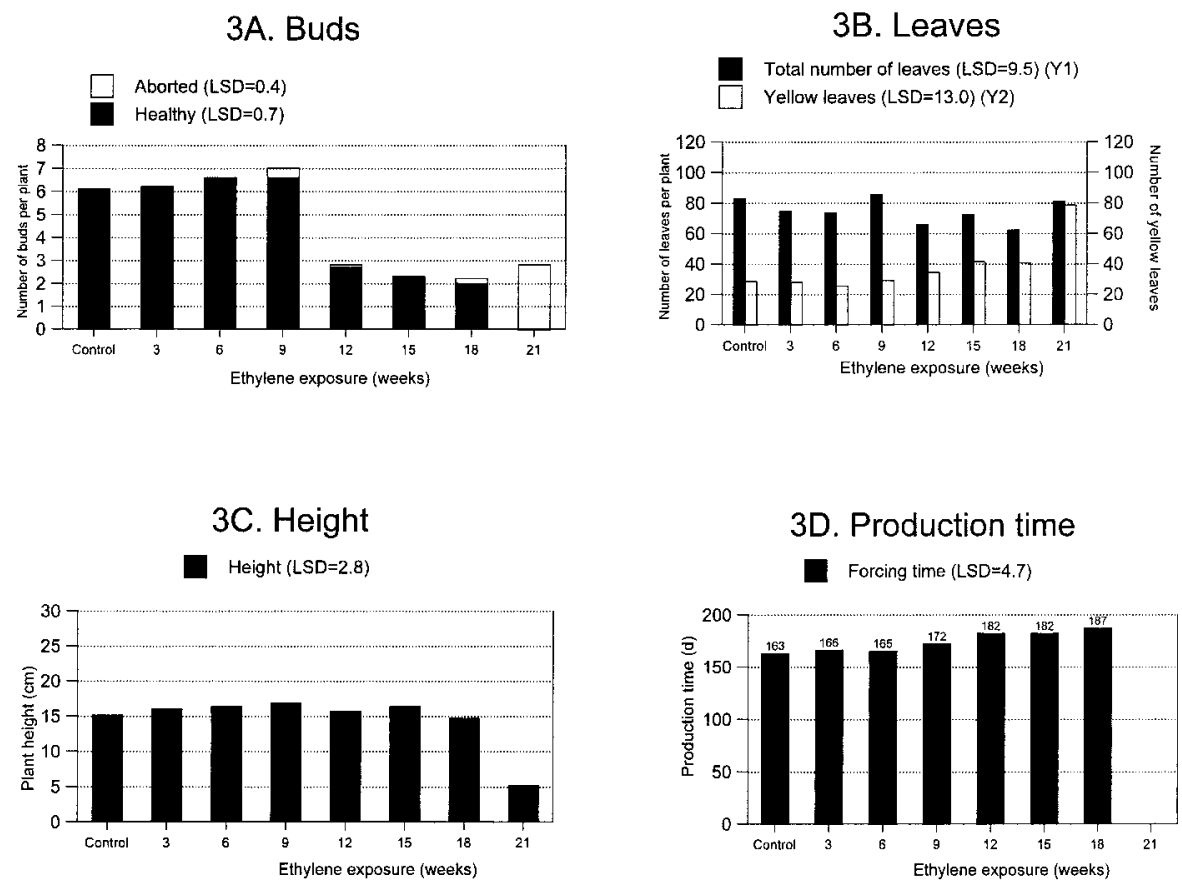

Fig. 3. The effect of timing of long-term exposure to ethylene on the number of buds (healthy and aborted), number of leaves (total and yellow), plant height, and production time (planting to flowering) for easter lily Nellie White'. Planting and exposure commenced 26 Oct. (week 0 ). Values for least significant difference (LSD) are indicated whenever significant by analysis of variance at $P \leq 0.05 .1 \mathrm{~cm}=0.4$ inches. 


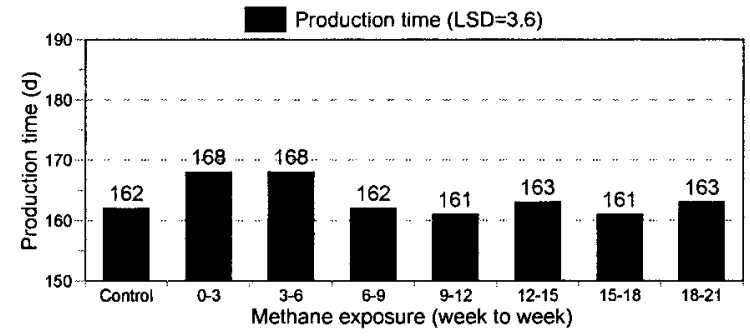

Fig. 4. The effect of short-term exposure (3 weeks) tomethane on production time for easterlily Nellie White'.Planting and start of exposures commenced 260ct. (week 0). Valuefor least significant difference (LSD) is indicated for significance by analysis of variance at $P \leq 0.05$.

ane until the end of vernalization, plants had 2 more buds, 20 more leaves and were $5 \mathrm{~cm}$ ( 2 inches) taller than the control, but had the same flowering date as the control treatment (data not shown). Exposure beyond the vernalization period produced even taller plants, but did not increase the number of leaves or buds compared with the short-term exposure treatment ending at the end of vernalization (week 6 to 9).

\section{Discussion}

Short-term or long-term exposures to ethylene before plants were moved to the greenhouse had no significant effect on the number of buds, leaves, or plant height, but delayed flowering by 1 week. The delay in flowering ( 1 week) was supported by Prince and Cunningham (1991), while they reported a decrease in bud number $(0.5$ per plant $)$ when bulbs were exposed to ethylene during vernalization.

A single 3-week period of ethylene exposure (at $2.4 \mu \mathrm{L} \cdot \mathrm{L}^{-1}$ ) during flower initiation (week 9 to 12 and week 12 to 15 ) reduced the number of healthy buds by 1 , while long-term exposures ending at the same dates reduced the number by three to four buds. It is unclear why the total number of buds was lower with the longterm compared to the short-term when both exposures ended during the floral initiation. There may be an accumulative effect within the plant tissue during longterm exposure resulting in fewer buds being initiated or, it is possible that with the short-term exposure during flower initiation, plants still initiated flower (secondary) buds after the end of exposure $(8$ Feb.). However, we did not determine whether flower initiation was completed on the same date with or without the presence of ethylene. Response is likely to be more severe and faster when the concentration of ethylene is increased.
The long-term exposure to ethylene during flower initiation delayed flowering by about 12 to 14 d compared to the shortterm exposure with the same ending date (Fig. 2D and 3D). Both short- and longterm exposure to ethylene after vernalization reduced stem diameter, especially at the basal part of the stem (data not shown), and stem diameter was positively correlated with leaf number (Pearson correlation coefficient, $\alpha=0.49$ at $P \leq 0.001)$.

Exposure to ethylene during the flowerdevelopment resulted inflowerbud abortion and shorter plants (Fig. 3A and 3C). Pants were shorter because of the reduced concentration of gibberellins normally produced by healthy flower buds that stimulate stem elongation at flowering (Wang and Breen, 1986).

Methane did not have the same detrimental effects on easter lilies as ethylene. Although short-term methane exposure did not affect the number of healthy flowers and leaves, plant height or forcing time, but long-term exposure until the end of vernalization(9weeks)increased the number of flower buds, leaves and plant height without affecting forcing time. The increased number of leaves, the result of continuous methane exposure is similar to the effects observed when lily bulbs are undercooled. The higher bud count achievedwithlong-term exposure through vernalization confirm the observation that easter lily bulbs with a higher number of leaves generally have more flower buds $(\alpha$

\section{A. Buds}
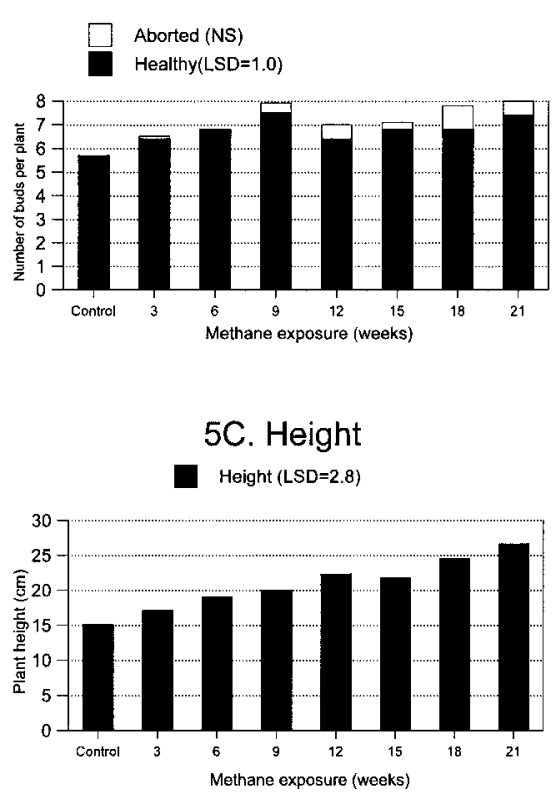

$=0.48$ at $P \leq 0.001)$, as well as a higher leaf unfolding rate.

Exposure to methane during flower development did not affect the percentage of yellow leaves in the same way as ethylene. Achieving a higher bud number was an interesting observation that could have commercial implications. In the future, commercial forcers may be able to use a smaller bulb size exposed to methane to produce a plant with a similar number of leaves and flower buds as alargersized bulb currently used without methane exposure. Further research will investigate the dosetime response of easter lilies as well as hybrid lilies to methane with both large and small bulbs.

\section{Literature cited}

Blankenship, S.M., D.A. Bailey, and J.E. Miller. 1993. The effects of continuous, low levels of ethylene on growth and flowering of easter lily. Scientia Hort. 53:311-317.

De Hertogh, A.A., H.P. Rasmussen, and N. Blakely. 1976. Morphological changes and factors influencing shoot apex development of Lilium longiflorum Thunb. during forcing. J. Amer. Soc. Hort. Sci. 101:463-471.

Mason, M.R. and W.B. Miller. 1991. Flower bud blast in easter lily is induced by ethephon and inhibited by silver thiosulphate. HortScience 26(9):1165-1167.

Prince, T.A. and M.S. Cunningham. 1991. Forcing characteristics of easter lily bulbs exposed to elevated-ethylene and-carbon dioxide and low-oxygen atmospheres. J.Amer. Soc. Hort. Sci. 116:63-67.

Rhoads, A., J. Troiano, and E. Brennen. 1973. Ethylene gas as a cause of injury to easter lilies. Plant Dis. Rpt. 57:10231024.

Wang, Y.-T. and P.J. Breen. 1986. Growth and photosynthesis of easter lily in response to flower bud removal. J. Amer. Soc. Hort. Sci. 111:442-446.

Wees, D. 1993. Effects of ethephon and ancymidol on plant height and flower abortion of easter lily. Can J. Plant Sci. 73:879-883.

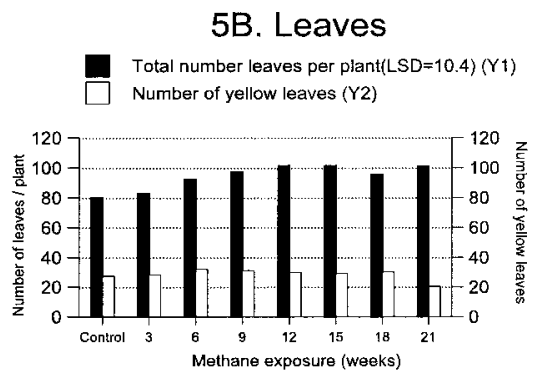

Fig. 5. The effect of long-term exposure to methane on number of buds (healthy and aborted), leaves (total and yellow) and plant height for easter lily Nellie White'. Planting and exposure commenced 26 Oct. (week 0 ). Values for least significant difference (LSD) are indicated whenever significant by analysis of variance at $P \leq 0.05 .1 \mathrm{~cm}=0.4$ inches. 